\title{
Letramento multimodal e construção conjunta de conhecimento na fala-em-interação ${ }^{1}$
}

\section{Multimodal Literacy and Joint Construction of Knowledge in Talk-in-Interaction}

Andréia Kanitz*

*Instituto Federal do Rio Grande do Sul - Campus Bento Gonçalves, Bento Gonçalves, Rio Grande do Sul / Brasil

*Universidade Federal do Rio Grande do Sul, Porto Alegre, Rio Grande do Sul / Brasil andreia.kanitz@bento.ifrs.edu.br

https://orcid.org/0000-0001-7056-9065

Raquel Leão Luz**

**Universidade Federal do Rio Grande do Sul, Porto Alegre, Rio Grande do Sul / Brasil raquelleaoluz@gmail.com

https://orcid.org/0000-0002-3479-6049

\begin{abstract}
RESUMO: Este trabalho tem por objetivo caracterizar um evento de letramento multimodal e demonstrar como, em tal evento, é possível flagrar o trabalho social e interacional de construção conjunta de conhecimento. Um segmento de fala-em-interação em que há engajamento dos participantes em uma atividade de leitura de um gráfico foi identificado e transcrito. A análise sequencial, focalizando os esforços dos participantes para darem conta da atividade de leitura, revelou que o segmento interacional constitui: a) um evento de letramento multimodal, em que os participantes negociam um procedimento de leitura de uma imagem (um gráfico), em um espaço de escrita que não o papel (a tela de um computador); e b) uma instância de construção conjunta de conbecimento na medida em que os participantes constroem conjuntamente um procedimento de leitura satisfatório para seus propósitos situados, que lhes possibilita obter com alguma precisão a informação em busca da qual estavam.
\end{abstract}

\footnotetext{
${ }^{1}$ Este artigo resulta de trabalho final elaborado para a disciplina de Seminário de Aquisição da Linguagem: uso da linguagem por crianças e adolescentes - interação, letramento e variação linguística, ministrada pela Profa. Dra. Luciene Juliano Simões, no Programa de Pós-Graduação em Letras da Universidade Federal do Rio Grande do Sul (UFRGS), no segundo semestre de 2011.
} 
PALAVRAS-CHAVE: letramento; letramento multimodal; evento de letramento; construção conjunta de conhecimento; interação face a face.

ABSTRACT: This study aims to describe a multimodal literacy event
and demonstrate how, in this event, it is possible to capture the social and
interactional work of joint construction of knowledge. The talk-in-interaction
segment analyzed consists in the reading of a chart in a technology lab. The
sequential analysis focuses on the participants' efforts to undertake the reading
activity, revealing that the interactional segment is: a) a multimodal literacy
event, in which the participants negotiate a procedure for reading an image (a
graphic), in a written space other than paper (the computer screen); and b) an
instance of joint construction of knowledge, considering that the participants
develop a satisfactory reading procedure for their situated purposes, which
enables them to obtain with some precision the information they are seeking. KEYWORDS: multimodal literacy; literacy event; joint construction of knowledge; talk-in-interaction.

\section{Introdução}

Neste trabalho buscamos, por meio da análise de um dado de falaem-interação, caracterizar, de modo situado, um evento de letramento ${ }^{2}$ multimodal e demonstrar como, em tal evento, ocorre e é possível flagrar o trabalho social e interacional de construção conjunta de conhecimento entre os participantes. Assim, na primeira seção propomos uma breve discussão acerca de noções de letramento que argumentamos estar relacionadas diretamente com o entendimento de letramento como atividade social, construída nas interações entre sujeitos e referenciada pela escrita ou por esferas de atividade em que a escrita, em suas diferentes modalidades de representação, está subjacente. Partimos, portanto, do conceito de letramento como "ato social" (BARTON, 2007; STREET, 2003) e discutimos a noção de letramento multimodal, a fim de propor uma reflexão sobre o modo como as interações entre participantes se configuram

\footnotetext{
${ }^{2}$ Os conceitos de evento de letramento e práticas de letramento estão estreitamente relacionados (STREET; CASTANHEIRA, 2014) e, por isso, costumam ser abordados conjuntamente nos estudos produzidos na área. Neste trabalho, no entanto, utilizaremos somente o termo evento de letramento com a finalidade de estabelecer um recorte analítico coerente do ponto de vista teórico e metodológico com a Análise da Conversa Etnometodológica (LODER, 2008).
} 
considerando novos espaços de escrita (virtual, digital) em que a leitura e a escrita medeiam a atividade interacional.

$\mathrm{Na}$ segunda seção, apresentamos uma perspectiva sociointeracional do trabalho de construção conjunta de conhecimento. Sendo assim, neste trabalho, partimos da compreensão de que momentos de construção conjunta de conhecimento constituem momentos de aprendizagem (ABELEDO, 2008; SALIMEN, 2009; GARCEZ; SALIMEN, 2011; GARCEZ; FRANK; KANITZ, 2012a), em que os participantes se engajam conjuntamente para dar conta de um objeto de aprendizagem tornado relevante por eles próprios na interação.

$\mathrm{Na}$ terceira seção apresentamos, em linhas gerais, os procedimentos metodológicos adotados e o campo de pesquisa no qual o segmento interacional analisado foi gerado. Por fim, na quarta seção, apresentamos o dado e sua análise, a partir da qual argumentamos que os participantes, envolvidos em um evento de letramento multimodal, produzem conhecimento conjuntamente na medida em que constroem conjuntamente, ao longo da interação, um procedimento de leitura de um gráfico em um espaço de escrita virtual.

\section{Sobre letramento e letramento multimodal}

Para que possamos analisar um dado de fala-em-interação como um evento de letramento ${ }^{3}$ multimodal, é necessário discutir os significados do letramento ${ }^{4}$ adotados neste artigo e pensar de que modo reverberam no entendimento da noção de letramento multimodal que aqui buscamos construir.

Para os fins desta pesquisa, partimos da noção de letramento como uma "atividade social" (BARTON, 2007; STREET, 2003), como um conjunto de práticas sociais mobilizadas por sujeitos situados em contextos socioculturais específicos, com o intuito de compreender os

\footnotetext{
${ }^{3}$ Neste trabalho entendemos como evento de letramento qualquer situação social em que o uso da escrita e/ou da leitura é constitutivo da interação. Trata-se de um recorte analítico que possibilita descrever e caracterizar quando, onde e como as pessoas leem ou escrevem, conversam sobre um texto escrito ou interagem por meio da escrita (STREET; CASTANHEIRA, 2014).

${ }^{4}$ Neste artigo, os termos letramento (no singular) e letramentos (no plural) são tomados como sinônimos e utilizados indistintamente.
} 
universos referenciados pela escrita nos quais circulam e dos quais tomam parte em suas interações cotidianas. Conforme Cook-Gumperz (2006), letramento é muito mais um fenômeno socialmente construído do que simplesmente a habilidade de ler e escrever. Letramento como um ato social é, ao mesmo tempo, ideologia construída historicamente e coleção de práticas comunicativas contextualmente incorporadas pelos sujeitos em suas comunidades de práticas.

Segundo Soares (2006), o letramento transforma o estado ou condição dos envolvidos, e essa mudança se manifesta nas esferas culturais, sociais, políticas e linguísticas. Assim, podemos conceber letramento como "estado" e como "processo". Ao estado está ligado o conjunto de práticas situadas, ligadas de algum modo à escrita, em que determinada comunidade se envolve, em determinado contexto histórico e que apresenta certa regularidade. Já ao processo liga-se a transformação dos usos históricos que as comunidades e também os indivíduos fazem da escrita.

Barton (2007) constrói um panorama acerca dos diversos sentidos relacionados à palavra letramento e aponta as dificuldades de traçar fronteiras definidas entre o que significa "letramento impresso", que tem na escrita sua materialidade, e outras formas de letramento requeridas pela complexidade das esferas de atuação dos sujeitos ou até mesmo pelas novas demandas educacionais. Elaborando um panorama conceitual do campo de estudos do letramento, o autor aponta importantes dimensões sobre o assunto, que estão intimamente relacionadas. A primeira delas é a de letramento como um conjunto de práticas socialmente organizadas em que se faz uso de sistemas simbólicos e de tecnologias (SCRIBNER; COLE, 1981). Letramento assim não significa conhecer como se lê e como se escreve, mas fazer uso desse conhecimento com propósitos específicos em contextos determinados. Do ponto de vista do sistema simbólico, letramento representa um conjunto de valores atribuídos à leitura e à escrita como atividades funcionais, tendo significado no mundo cultural. Do ponto de vista da tecnologia, a escrita se configura como técnica de registro, como ferramenta para atingir determinados objetivos em certos contextos. Apesar de haver um paradigma psicológico implicado nessa definição, leitura e escrita estão socialmente contextualizadas.

Outra importante dimensão do letramento discutida em Barton (2007), que neste artigo ganha maior ênfase, é a que o define essencialmente em termos de práticas sociais (STREET, 1984, 2003). Essa abordagem, 
mais ideológica, supõe letramento como algo que varia a cada situação, associado à ideologia. Sob esta perspectiva o uso da escrita, por exemplo, é tornado relevante também na oralidade dos sujeitos, não é vista de modo restrito. Street (1984) propõe o modelo ideológico em contraste ao modelo autônomo de letramento, que é definido separadamente do contexto social. Sob o ponto de vista do modelo autônomo, há dicotomia entre oral e escrito, retirando a oralidade de sua relação com o texto, por ser subjetiva e por ser construída e reconstruída no momento da interação. Para o autor, o letramento não é dado de modo neutro, e seus efeitos sociais não são experienciados posteriormente a interações; portanto, o letramento é sempre uma atividade social ideológica construída nas interações.

Em resumo, letramento é ato social, mediado pelas interações entre participantes e por suas relações com os textos, podendo ser mais bem descrito como "práticas de letramento", que se configuram na vida cotidiana em "eventos" (BARTON, 2001, 2007). Sobre a definição de práticas e eventos de letramento, Barton (2007) explica que as práticas são os padrões culturais comuns de uso da leitura e da escrita em uma situação particular, ou seja, as pessoas trazem para as atividades de leitura e escrita seu conhecimento cultural, determinando os modos de usar o letramento em eventos de letramento. Estes, por sua vez, são atividades particulares em que o letramento tem um papel, e essas atividades podem ter certa regularidade. Discutir um texto em aula, contar uma história para uma criança, ler uma notícia de jornal e comentar em uma roda de amigos são eventos de letramento, porque envolvem diretamente interações mediadas pela escrita em que os sujeitos lançam mão de seus modos de agir pela linguagem para participarem das ações construídas nas interações. Além desses exemplos, há outros em que a escrita não ocupa papel central, mas está incorporada em outras formas de expressão (como a visual); nesses casos, trata-se de eventos e práticas de letramento multimodal. Ler (ou produzir) um aviso em um mural que apresenta a imagem de proibição do uso de celular, ler infográficos em páginas da internet, ler textos na tela do computador (hipertextos) são exemplos de eventos de outra dimensão do letramento - a da multimodalidade.

Conforme Heath e Street (2008), o termo "letramento multimodal" é utilizado, portanto, para se referir a eventos e práticas em que a escrita ainda é muito saliente, mas se apresenta incorporada também em outros modos de representação do mundo. Conforme explicam os autores, a 
multimodalidade de letramento pode ser observada em contextos em que agentes, organizações, instituições querem informar, entreter, mudar atitudes ou alcançar todos esses objetivos ao mesmo tempo, utilizando recursos gráficos, visuais, auditivos, virtuais.

Assim, podemos falar de letramentos, no plural, visto que cada modalidade de letramento, que está para além do material escrito/impresso em papel, apresenta diferentes "espaços de escrita", 5 modos diversos de produzi-la, de fazê-la circular e, sobretudo, diferentes maneiras de interagir pela escrita. De acordo com Soares (2002, p. 155-156),

essa necessidade de pluralização da palavra letramento e, portanto, do fenômeno que ela designa já vem sendo reconhecida internacionalmente, para designar diferentes efeitos cognitivos, culturais e sociais em função ora dos contextos de interação com a palavra escrita, ora em função de variadas e múltiplas formas de interação com o mundo - não só a palavra escrita, mas também a comunicação visual, auditiva, espacial.

Assim, nas páginas seguintes buscamos caracterizar um dado de falaem-interação como um evento de letramento multimodal, em que formas de interagir pela escrita e por outras modalidades de representação gráfica estão envolvidas.

\section{Construção conjunta de conhecimento: uma perspectiva sociointeracional}

Além de caracterizar um evento de letramento multimodal por meio da análise de um dado de fala-em-interação, este artigo tem também por objetivo demonstrar como, em um tal evento, pode ocorrer o que nesta seção procuramos definir em linhas gerais como trabalho de construção conjunta de conhecimento. O que pretendemos, portanto, é caracterizar um evento de letramento multimodal enquanto atividade em que há e é possível flagrar a construção conjunta de conhecimento entre os participantes na fala-em-interação.

\footnotetext{
${ }^{5}$ Conforme Soares (2002, p. 149), "todas as formas de escrita são espaciais, todas exigem um 'lugar' em que a escrita se inscreva/escreva, mas a cada tecnologia corresponde um espaço de escrita diferente. [...] Nos primórdios da história da escrita, o espaço de escrita foi a superfície de uma tabuinha de argila [...] Atualmente, com a escrita digital, surge este novo espaço de escrita: a tela do computador". (grifos nossos).
} 
Partimos da compreensão de que momentos de construção conjunta de conhecimento constituem momentos de aprendizagem (ABELEDO, 2008; SALIMEN, 2009; GARCEZ; SALIMEN, 2011; GARCEZ; FRANK; KANITZ, 2012b). Nesses termos, entendemos que o trabalho de construir conhecimento constitui um fenômeno social, uma vez que envolve pelo menos mais de um participante, e interacional, dado que é na interação entre os participantes reunidos que o conhecimento se constrói. Tal fenômeno, assim como todo fenômeno interacional, constitui uma realização pública conjunta, observável nas ações que os próprios participantes realizam em interação com o outro.

Além disso, o trabalho de construir conhecimento constitui, na perspectiva aqui adotada, uma realização emergente e contingente que depende das demandas colocadas aos participantes no aqui-e-agora da interação. É no aqui-e-agora que o conhecimento é construído pelos atores sociais, realizadores de ações, para atender aos fins práticos, contingentes e emergentes das atividades em que se envolvem.

Adotamos aqui um entendimento de construção conjunta de conhecimento que é passível de descrição mediante a análise situada da orientação dos participantes para essa atividade em suas ações. Trata-se, portanto, de uma realização social, instanciada na interação mediante ações sequencialmente organizadas, em que participantes, engajados conjuntamente, procuram dar conta de um objeto tornado relevante por eles próprios e, assim, se envolvem na construção conjunta de algo novo, um entendimento novo, que se constitui interacionalmente como socialmente compartilhado. Em suma, trata-se de um trabalho (a) social e (b) interacional em que há, além de (c) visível engajamento em torno de um empreendimento comum, (d) a produção pública e local de um entendimento entre os participantes que empreendem esforços (e) para dar conta de um objeto que eles tornam relevante em suas ações.

Dado o entendimento até aqui exposto, de que é na interação social que a construção do conhecimento se instancia, partimos de uma visão de linguagem indissoluvelmente ligada à interação social e à cognição (ABELEDO, 2008), compreendendo que a cognição, ao contrário de individual, é socialmente compartilhada e, portanto, indissociável do uso da linguagem na interação.

É nesses termos que adotamos uma perspectiva praxeológica de cognição, também entendida como uma realização pública, instanciada 
na interação entre os participantes na medida em que eles se orientam para essa atividade em suas ações, por meio da linguagem (SCHEGLOFF, 1991; MONDADA; DOHELER, 2004; MAYNARD, 2006; MONDADA, 2006; ABELEDO, 2008; SALIMEN, 2009). Nessa perspectiva, conforme Frank (2010), a cognição, longe de se referir a conhecimentos abstratos na mente dos indivíduos, "é entendida como socialmente distribuida, pois o que as pessoas sabem é o que elas sabem em comum” (p. 17, grifos nossos), sendo esse conhecimento em comum ativamente construído na interação. Assim, "uma vez que, para interagir, as pessoas precisam se valer do uso da linguagem, é na fala-em-interação que a produção e manutenção da cognição vai ser investigada" (FRANK, 2010, p. 17). De acordo com essa perspectiva, a cognição, sendo socialmente distribuída, torna-se pública à medida que as pessoas interagem umas com as outras ao trabalharem para manter um mundo em comum entre elas.

Além disso, compartilhamos do entendimento formulado por Antaki (2006) de que a cognição, o que os participantes sabem, é uma questão prática, que depende dos propósitos da atividade realizada e do que os participantes fazem para reconhecer "uma cognição". Esse entendimento permite abordar a construção conjunta de conhecimento a partir do que os participantes fazem de fato nos eventos interacionais analisados, levando em conta o caráter situado de cada interação.

\section{Procedimentos metodológicos: segmentação, transcrição e análise do dado pela perspectiva dos participantes}

Os procedimentos metodológicos adotados neste trabalho se inscrevem na Análise da Conversa Etnometodológica (ACE), perspectiva teórico-metodológica voltada para o estudo da ação social humana situada no espaço e no decorrer do tempo real. As pesquisas em ACE buscam, pela análise cuidadosa de dados naturalísticos de fala-em-interação, entender como os atores sociais se organizam para juntos produzirem ações pelo uso da linguagem e, assim, alcançarem um entendimento compartilhado sobre o que estão fazendo em conjunto ao longo da interação (ATKINSON; HERITAGE, 1984; LODER; JUNG, 2008).

É no tratamento minucioso de dados empíricos de interação que se concentra fundamentalmente o trabalho do analista da conversa. Conforme sintetiza Loder (2008), é olhando para os dados que o analista "encontra fonte 
de evidências para suas análises e explicações sociais” (p. 127). Constituído o corpus, o tratamento dos dados passa a ser, então, tarefa primordial do analista da conversa, tarefa essa que costuma envolver centralmente quatro procedimentos metodológicos: visualização, segmentação, transcrição e análise dos dados.

Para realizar este trabalho partiu-se de um corpus de cerca de 60 horas de gravações audiovisuais geradas em um laboratório de tecnologia voltado à produção de materiais biomédicos, a fim de saber como se dá a produção de conhecimento em atividades de fala entre participantes dedicados a tarefas de produção de conhecimento com propósitos de desenvolvimento de tecnologia (GARCEZ, 2010, p. 7). ${ }^{6}$ O conjunto de registros foi inicialmente visualizado buscando identificar momentos de engajamento dos participantes em alguma atividade de leitura que pudesse configurar um evento de letramento multimodal em que fosse possível flagrar o trabalho de construção conjunta de conhecimento. A partir das instâncias levantadas ao longo da visualização, foi selecionado um segmento de fala-em-interação em que os participantes, em busca de uma informação, envolvem-se na leitura de um gráfico encontrado em um artigo científico.

O segmento foi transcrito de acordo com o modelo Jefferson de transcrição ${ }^{7}$ (LODER, 2008), acrescido de quadros de imagens contemplando aspectos não verbais da interação. A transcrição foi realizada a partir dos registros de áudio e vídeo obtidos por meio de duas câmeras de filmagem. Em função de sua extensão, um trecho do segmento foi narrado por meio de vinheta narrativa. Além disso, alguns pequenos trechos de transcrição foram omitidos e substituídos por curtas narrativas, entremeadas na prosa analítica. O método de análise do segmento privilegiou a perspectiva dos próprios participantes acerca do que fazem em conjunto, focalizando as ações para as quais eles se orientam turno a turno de modo a levarem a cabo a atividade de leitura do gráfico em que estão envolvidos.

\footnotetext{
${ }^{6}$ Para maiores informações acerca do cenário e interesses de pesquisa que motivaram essa geração de dados, ver Garcez, Frank e Kanitz (2012b).

${ }^{7}$ As convenções de transcrição Jefferson utilizadas nos excertos de transcrição reproduzidos aqui se encontram no Anexo A.
} 


\section{5 “O nosso problema é que não temos a energia de ativação do nitinol": letramento multimodal e construção de conhecimento na fala-em-interação}

Uma das principais frentes de pesquisa no laboratório de tecnologia investigado tem buscado obter, pioneiramente, por meio de metalurgia do pó, ${ }^{8}$ uma liga metálica amplamente utilizada na produção de materiais biomédicos: o nitinol (NiTi). ${ }^{9}$ Trata-se de uma liga de excelente biocompatibilidade composta por átomos de níquel (Ni) e de titânio (Ti) que se unem a uma determinada energia mínima, denominada energia de ativação (Ea). No segmento interacional analisado nesta seção, os participantes engajam-se justamente na busca pelo valor da Ea do nitinol, envolvendose conjuntamente na identificação desse valor pela leitura de um gráfico encontrado em um artigo científico. Nesse empreendimento conjunto, que aqui caracterizamos como um evento de letramento multimodal, os participantes constroem conhecimento conjuntamente na medida em que constroem em conjunto um procedimento de leitura do gráfico que lhes possibilita obter com alguma precisão o valor da Ea da liga.

No segmento analisado a seguir, Éverton e Tatiana ${ }^{10}$ são os participantes centrais. Cabe, no entanto, explicitar que ao final do segmento, um terceiro participante junta-se a eles. Em atendimento a um pedido de ajuda realizado por Éverton, Saulo junta-se a seus colegas de laboratório na construção de um procedimento de leitura que lhes possibilite obter a informação em busca da qual estão. Nesses termos, Éverton, Tatiana e Saulo

\footnotetext{
${ }^{8}$ A metalurgia do pó é um processo de fabricação de peças metálicas em escala comercial, aplicando-se pressão sobre pós metálicos ou cerâmicos ultrafinos. Trata-se de um processo em franca expansão na atualidade. Por meio dele é possível fabricar peças para praticamente todos os ramos da indústria.

${ }^{9}$ Nitinol é o nome comercial da liga. O material foi descoberto na década de 1960 no Laboratório de Material Bélico Naval dos EUA, localizado em White Oak, Maryland. O nome da liga é composto pelos símbolos químicos dos elementos (Ni, Ti), junto com a sigla do laboratório Naval Ordnance Laboratory (NOL).

${ }^{10} \mathrm{O}$ segmento interacional analisado neste artigo foi gerado mediante preenchimento e assinatura de consentimento informado pelos participantes, autorizando as filmagens. Os participantes da pesquisa são identificados por pseudônimos, atribuídos com a finalidade de preservar suas identidades e de evitar a imposição de categorizações a priori (LODER, 2008; GARCEZ, 2002).
} 
demonstram interacionalmente que recorrer a um terceiro participante é um recurso disponível para superar entraves que se colocam no curso das atividades. $^{11}$

O segmento tem início quando os participantes Éverton e Tatiana iniciam a resolução de uma equação matemática e se dão conta de que precisam da Ea do nitinol para compor o cálculo. Coloca-se, então, um problema: os participantes não possuem essa informação, por isso precisam buscá-la. É Éverton quem inicialmente expõe a Tatiana a falta dessa informação necessária para iniciar o cálculo, e é diante desse fato que os dois participantes iniciam uma pesquisa em busca do valor da Ea da liga, conforme acompanhamos no Excerto 1 (linhas 01-29).

\section{Excerto 1}

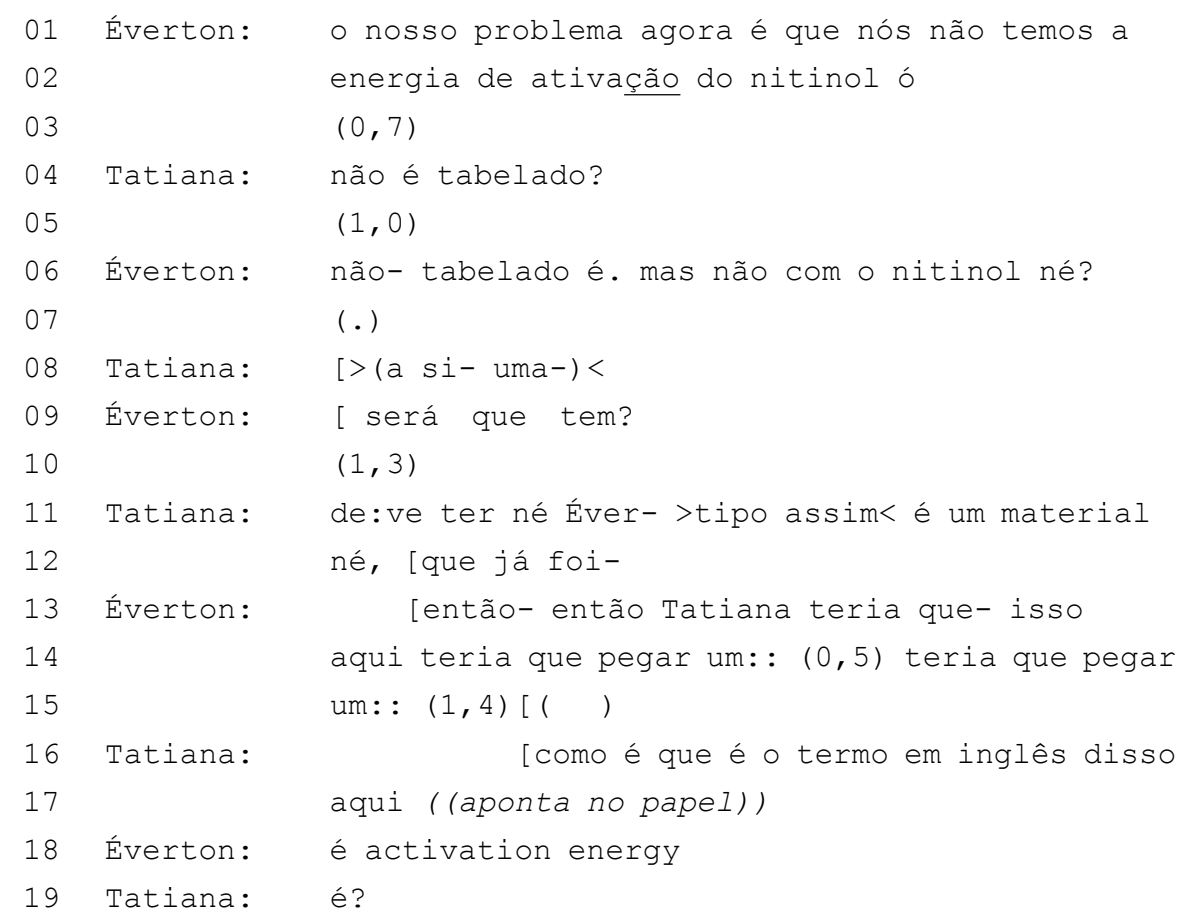

\footnotetext{
${ }^{11}$ Queremos agradecer à Profa. Luciene Simões por ter chamado nossa atenção, em uma análise inicial do dado, para a necessidade de destacar desde o princípio Saulo como um dos participantes do segmento. Muito obrigada pela leitura sempre atenta!
} 


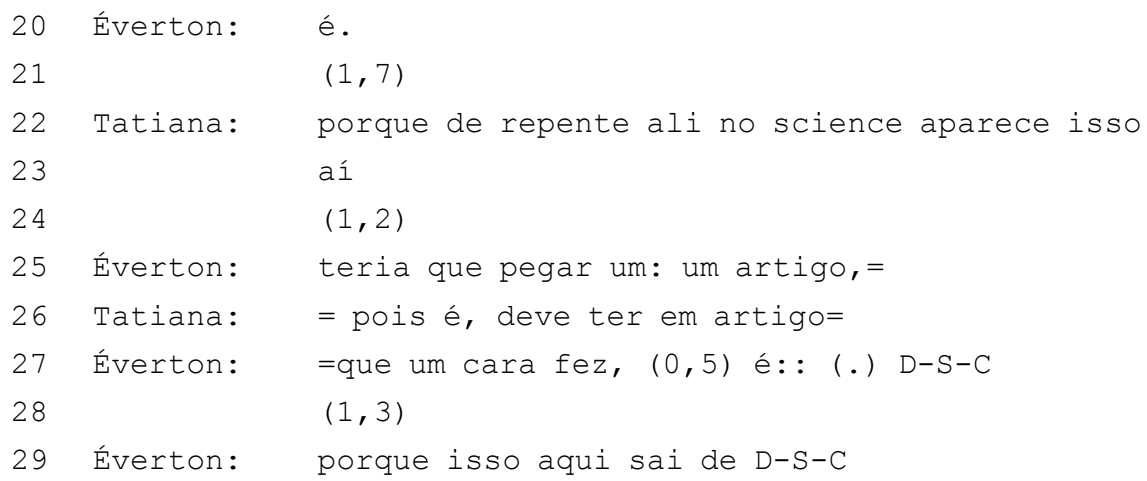

Diante do problema formulado por Éverton, Tatiana pergunta-lhe se o valor da Ea do nitinol não seria tabelado, ao que seu interlocutor responde sim, existe uma tabela com os valores de Ea para o níquel e para o titânio, mas não para a liga. Entretanto, logo depois Éverton retoma a questão e indaga Tatiana a respeito da possibilidade de encontrar o valor da Ea da liga: "será que tem?" (linha 9), ao que sua interlocutora responde: "de:ve ter né Éver->tipo assim< é um material né, que já foi" (linhas 11 e 12).

A partir desse momento, os dois participantes engajam-se conjuntamente na procura pela informação que lhes falta. Entre as linhas 13 e 29 eles dão início à busca: Éverton sugere procurar algum trabalho que apresente um DSC do nitinol, já que, segundo ele, é em DSC que a informação de Ea pode ser obtida. Por seu turno, Tatiana sugere uma busca no portal de periódicos Science pelo termo activation energy como outra opção. A vinheta narrativa a seguir reproduz em prosa narrativa nossa observação do episódio de cerca de 30 minutos em que Éverton e Tatiana buscam algum artigo científico que lhes apresente a informação necessária. 


\section{A busca por um artigo que apresente o valor da energia de ativação do nitinol}


Diante da falta da informação, os dois participantes iniciam, em seus computadores, a busca por algum artigo científico a partir do qual possam obter o valor procurado: Éverton procura algum artigo que apresente um gráfico de DSC do nitinol, enquanto Tatiana busca artigos em seus arquivos. Em meio a essa busca inicial, Éverton compartilha com Tatiana a lembrança da existência de um artigo de revisão sobre o nitinol que talvez contenha a informação procurada. Ela também se recorda e comenta que estava vendo um artigo sobre a fabricação do nitinol, mas que não encontrou nele a informação. Os dois participantes vão, então, em busca do artigo de revisão apontado por Éverton, cada um realizando a pesquisa em seu próprio computador; Éverton procura em seu e-mail, enquanto Tatiana prossegue em suas pastas de artigos. Ela

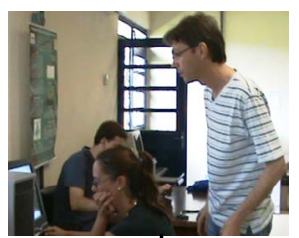
encontra um artigo e lê seu título para Éverton. O participante lhe responde dizendo que não se trata do trabalho por ele mencionado. Tatiana, então, afirma que não há em meio aos seus arquivos um artigo de revisão. Éverton comenta que talvez tenha encontrado o arquivo em seu e-mail, mas que não está conseguindo realizar o download. Diante disso, Tatiana oferece seu computador para carregar o arquivo. Éverton dirige-se até Tatiana. Os dois participantes tentam localizar o artigo na internet por meio de um site de busca; no entanto, não o encontram. Éverton solicita a Tatiana que faça uma busca por physical metal proprieties nitinol no portal Science, e volta a se sentar em frente ao seu computador. Tatiana realiza a busca por cerca de 10 minutos. Depois de pesquisar, a participante diz ter encontrado dois artigos que apresentam DSC com informações sobre Ea. Os dois participantes voltam a se sentar lado a lado, em frente ao computador de Tatiana, para juntos verificarem os artigos


por ela encontrados. Depois da verificação conjunta do conteúdo dos artigos, Éverton destaca que os textos encontrados tratam da liga $\mathrm{Ti}_{2} \mathrm{Ni}$ e não do nitinol propriamente. Ele esclarece, então, para Tatiana que a busca é pela Ea do nitinol (NiTi), liga com 50\% de átomos de níquel na composição, e não 33\%, como na liga $\mathrm{Ti}_{2} \mathrm{Ni}$. Depois de mais alguns minutos verificando os artigos encontrados por Tatiana, Éverton sugere que é possivel utilizar um dos gráficos de DSC da liga Ti $i_{2}$ Ni encontrado para identificar a Ea do nitinol.

\section{A vinheta narrativa retrata o episódio em que Tatiana e Éverton se engajam na busca por algum artigo a partir do qual possam obter a}


informação procurada: o valor referente à Ea do nitinol. Essa é uma busca realizada colaborativamente: os dois participantes avançam na procura, e é por meio da contribuição de cada um que a pesquisa progride. Depois de terem realizado buscas em e-mail, em arquivos no computador e, por fim, no portal de periódicos Science durante cerca de 30 minutos, os dois participantes encontram em um artigo um gráfico de DSC que julgam ser válido para identificar o valor da Ea procurado. O gráfico encontrado trata de uma liga metálica que, apesar de ser composta - assim como o nitinol - também por átomos de níquel e titânio, distingue-se pelo percentual de átomos dos elementos. Trata-se de um gráfico de DSC da liga metálica $\mathrm{Ti}_{2} \mathrm{Ni} \cdot{ }^{12}$

Nesse gráfico são apresentados diferentes valores de Ea para diferentes concentrações de átomos de níquel na composição. No eixo ' $x$ ' estão apresentados os percentuais de átomos de níquel, e no eixo ' $y$ ', os valores de Ea correspondentes (Figura 1).

FIGURA 1 - Gráfico encontrado pelos participantes

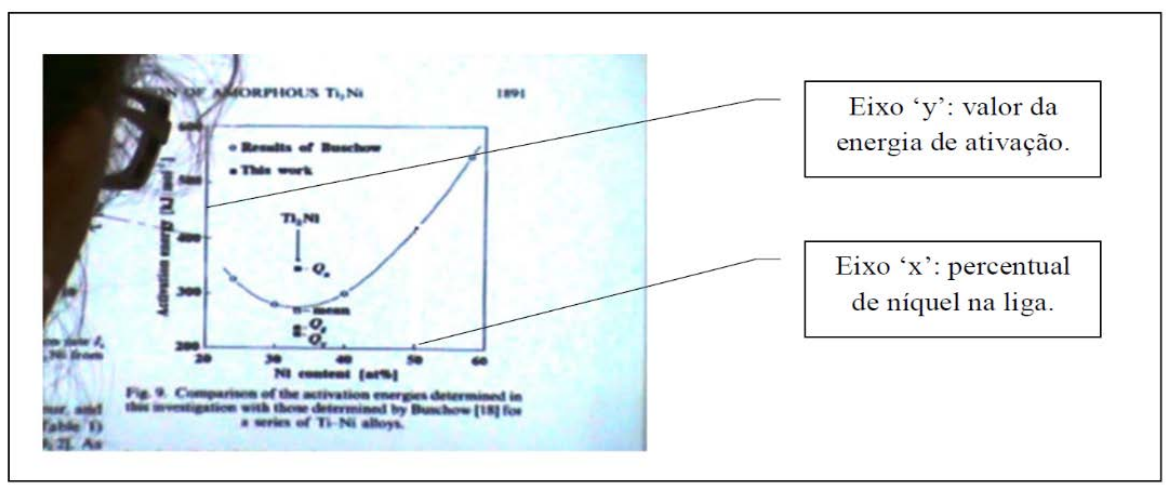

Fonte: Imagem captada a partir dos registros audiovisuais.

Embora o gráfico não apresente diretamente a informação do valor da Ea procurado, os participantes concordam com a possibilidade de obtê-la por meio da curva apresentada no gráfico. A partir da concentração de $50 \%$ de átomos de níquel sinalizada no eixo ' $x$ ' - percentual presente na liga de nitinol sendo desenvolvida pelos pesquisadores, os participantes procurarão

\footnotetext{
${ }^{12}$ A liga Ti 2 Ni apresenta 33\% de níquel e 65\% de titânio, enquanto o nitinol (NiTi), entre 48 e $60 \%$ de níquel e o restante de titânio.
} 
determinar, pela leitura conjunta do gráfico, o valor da Ea correspondente no eixo ' $y$ ' (Figura 2)

FIGURA 2 - Valor da energia de ativação a ser determinado no eixo 'y'

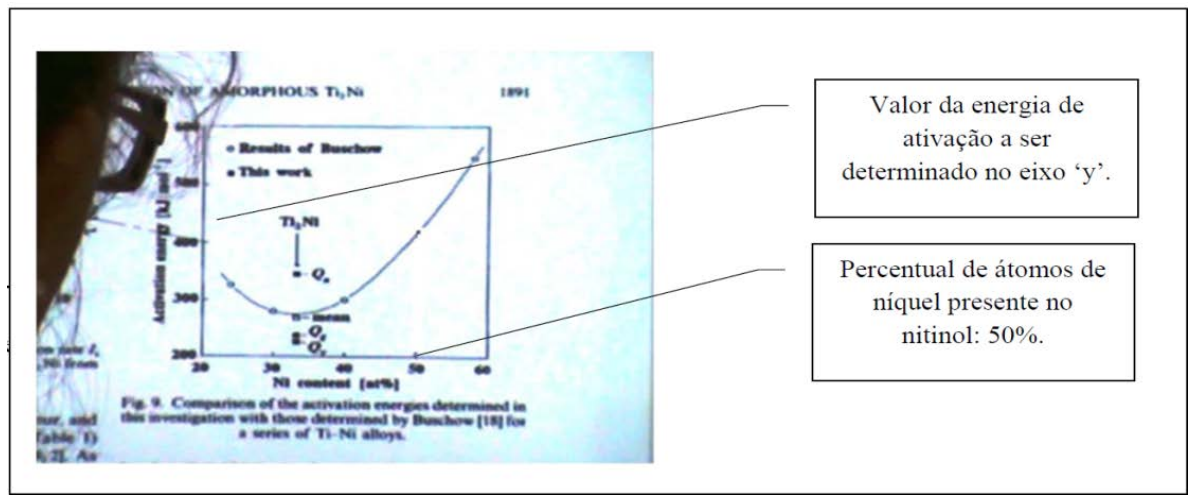

Fonte: Imagem captada a partir dos registros audiovisuais, acrescida de retas correspondentes aos eixos ' $x$ ' e ' $y$ '.

É por meio da leitura conjunta desse gráfico - atividade que aqui buscamos caracterizar como um evento de letramento multimodal - que os participantes Éverton e Tatiana, com a colaboração final de um terceiro participante, Saulo, irão buscar o valor exato da Ea do nitinol. Engajados nesse empreendimento, os participantes constroem conjuntamente um procedimento de leitura que lhes permita alcançar de modo preciso a informação que lhes falta para seguir adiante no cálculo da equação em que estavam envolvidos no início deste segmento interacional.

Em momento imediatamente seguinte ao episódio narrado na vinheta, Tatiana concorda com a sugestão apresentada por Éverton de utilizar um gráfico de DSC da liga $\mathrm{Ti}_{2} \mathrm{Ni}$ para determinar o valor da Ea que estão buscando. $\mathrm{O}$ valor estimado pelos participantes apenas pela análise visual do gráfico, sem nenhuma medição precisa, é de aproximadamente 400 quilojoule por $\mathrm{mol}(\mathrm{kJ} / \mathrm{mol})$, conforme o Excerto 2: 


\section{Excerto 2}

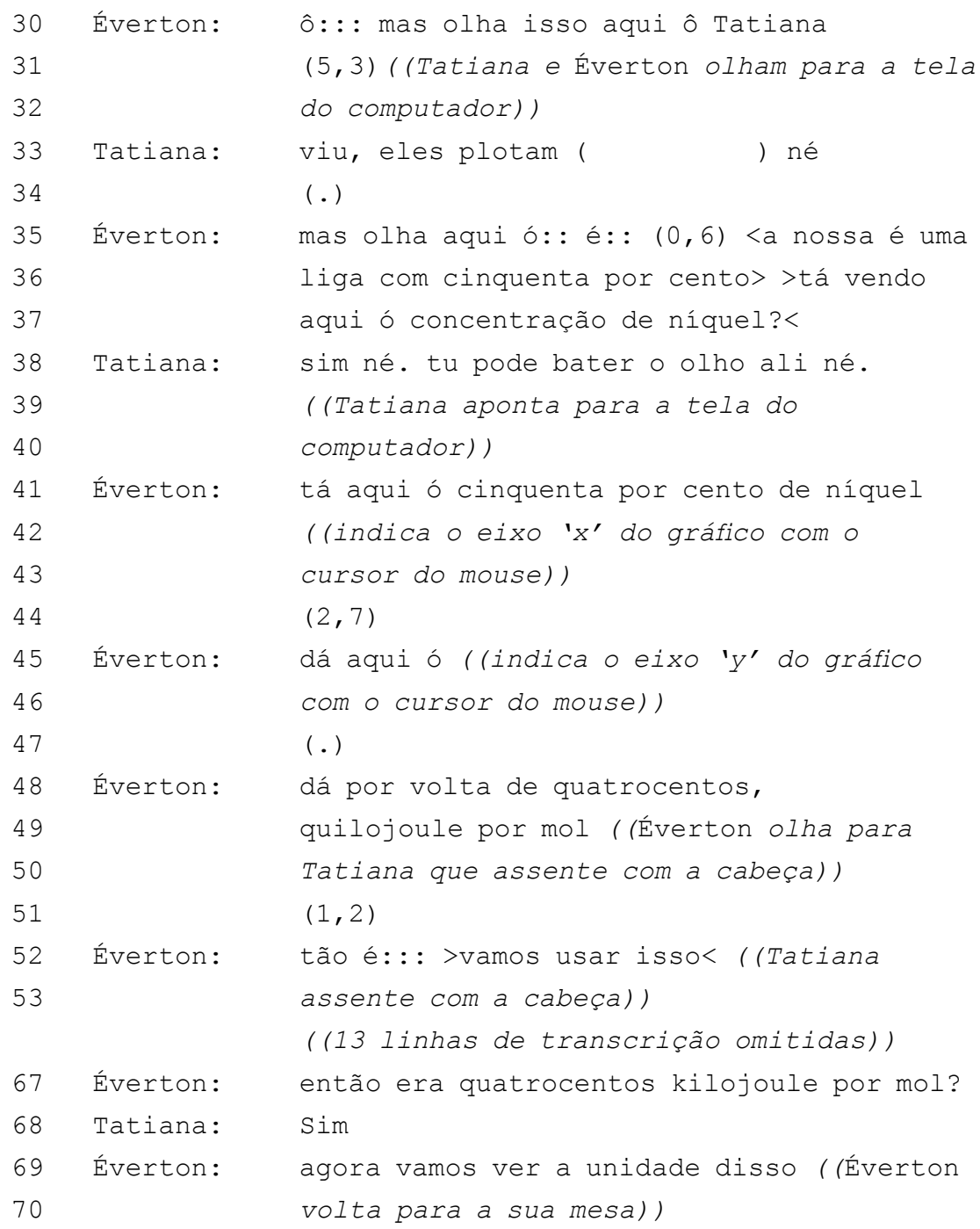

Entre as linhas 30 e 37, Éverton apresenta a possibilidade de utilizarem o gráfico encontrado para determinar o valor da Ea a partir do percentual de $50 \%$ de níquel indicado no eixo ' $\mathrm{x}$ ', possibilidade com a qual Tatiana concorda quando diz "sim né. tu pode bater o olho ali né." (linha 38). Entre as linhas 41 e 49, Éverton expande a sugestão apresentada, indicando os eixos do gráfico na tela do computador (Figura 
3). Segundo ele, o valor da Ea da liga, em uma composição com $50 \%$ de níquel, seria de aproximadamente $400 \mathrm{~kJ} / \mathrm{mol}$, leitura com a qual Tatiana concorda inicialmente ao assentir com a cabeça (linha 50).

FIGURA 3 - Sugestão de Éverton

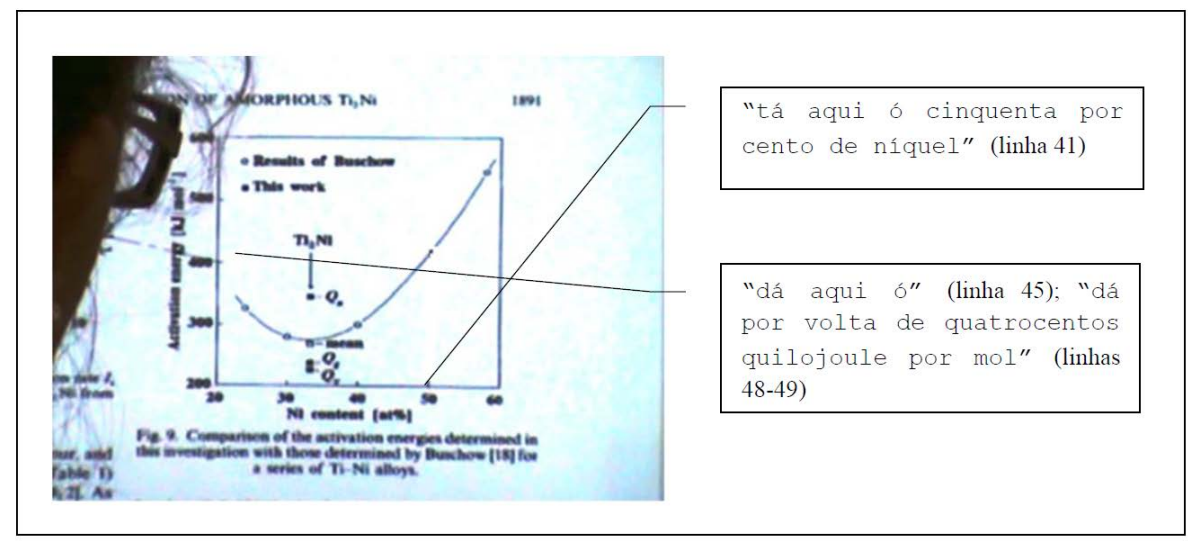

Fonte: Imagem captada a partir dos registros audiovisuais.

Nas linhas 52 e 53 os dois participantes concordam em utilizar a informação do valor de Ea apresentada pelo gráfico. Depois de 13 linhas de transcrição omitidas, em que Éverton e Tatiana conversam sobre o salvamento dos artigos encontrados, Éverton checa com Tatiana o valor aproximado encontrado: "então era quatrocentos quilojoule por mol?" (linha 67). Depois da confirmação de sua interlocutora, Éverton propõe o próximo passo, encontrar a unidade de medida de energia solicitada pela equação: "agora vamos ver a unidade disso" (linha 69).

Durante cerca de 5 minutos os participantes buscam verificar se a unidade de medida da Ea fornecida pelo gráfico corresponde à unidade solicitada na equação. Concluída a verificação, os participantes se certificam de que a unidade $\mathrm{kJ} / \mathrm{mol}$ no gráfico é a mesma solicitada no cálculo, o que permite continuar a resolução. Éverton, entretanto, logo em seguida se orienta para a necessidade de confirmarem o valor apenas estimado inicialmente (Excerto 3). 


\section{Excerto 3}

132 Éverton:

133

134 Tatiana:

135

136 Éverton:

137 Tatiana:

138 Éverton:

140

144 Tatiana:

148 Éverton:

151 Tatiana:

152 Éverton:

153 Tatiana:

157 Éverton:

158 Tatiana:

161 Tatiana:

162 Éverton:

163 Tatiana:

165 Éverton:

\section{((61 linhas de transcrição omitidas))}

\section{tá. então dá pra fazer}

(.)

(aí tu vê)

(.)

viu só- [é: : (.)=

$$
\left[\left({ }^{\circ} \mathrm{fala}{ }^{\circ}\right)\right.
$$

=precisaria saber aquele quatrocentos, vamos ver se- >vamos só confirmar aquilo?<

$(21,0)$ ((Éverton volta a sentar-se ao lado de Tatiana em frente ao computador. Voltam a procurar o gráfico no artigo.))

ai deixa eu botar um reguinha aí ou uma folha $(8,0)$ ( Tatiana pega um pedaço de papel e o posiciona sobre o eixo ' $y$ ' do gráfico na tela do computador))

$\left({ }^{\circ}\right.$ esse aqui ó ${ }^{\circ}$ tem que usar primeiro essa aqui ó (lcoloca um pedaço de papel sobre o eixo ' $x$ ')) ah sim. escala tá. É deixa eu pegar um outro ((Tatiana pega outro papel e o posiciona sobre o eixo ' $y^{\prime}$ )) $(4,2)$ ( (Éverton e Tatiana tentam medir o gráfico com dois pedaços de papel)) Andréia não filma agora ((Éverton sorri)) é ((Tatiana sorri. Saulo dirige o olhar para Tatiana e Éverton))

(.)

não. é: : é me [nos

[não. é quatrocentos

quatrocentos tu acha que é? >é que tu tá olhando de frente e eu tava olhando de lado< você tava de lado 




Conforme podemos acompanhar no Excerto 3, depois de Éverton expressar a necessidade de confirmar o valor de $400 \mathrm{~kJ} / \mathrm{mol}$ (linhas 138140), os participantes dão início a uma leitura mais detida do gráfico, experimentando alguns procedimentos de medição. Para isso, Éverton volta a se sentar ao lado de Tatiana em frente ao computador. Depois de procurarem e novamente encontrarem o gráfico (linhas 141-143), Tatiana sugere que utilizem uma régua ou um pedaço de papel para medir: "ai deixa eu botar um reguinha aí ou uma folha" (linha 144), orientando-se para necessidade de traçarem retas sobre os eixos para poderem encontrar o valor com alguma precisão. A participante, então, pega um papel e o posiciona na tela do computador, sobre o eixo ' $y$ ' do gráfico (linhas 145-147).

Logo em seguida, Éverton corrige o procedimento de sua interlocutora, instruindo-a a colocar o pedaço de papel sobre o eixo ' $x$ ' primeiramente: " $\left({ }^{\circ}\right.$ faz assim $\left.0^{\circ}\right)$ tem que usar primeiro essa aqui ó" (linhas 148-150). Tatiana ratifica a instrução de Éverton (linha 150) e diante disso pega outro pedaço de papel que possa ser posicionado então sobre o eixo ' $y$ ' (linhas 153-154), completando, assim, o traçado improvisado das retas sobre os eixos. De posse de dois pedaços de papel, os participantes tentam medir o gráfico, posicionando-os sobre os eixos, para encontrar uma medida mais exata do valor da Ea procurado (Figura 4). 
FIGURA 4 - Traçado de retas sobre a imagem do gráfico improvisado com pedaços de papel

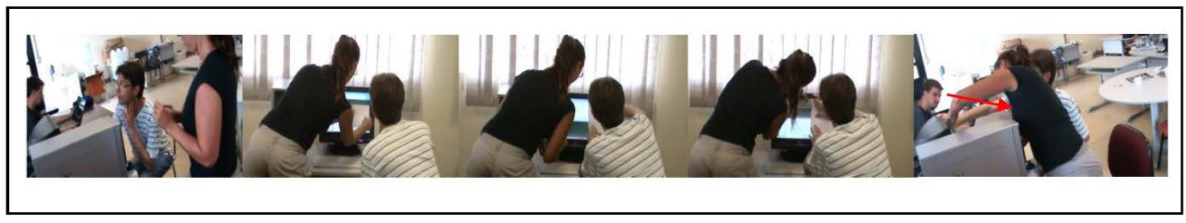

Fonte: Imagens captadas a partir dos registros audiovisuais.

Entre as linhas 155 e 159, enquanto procuram confirmar o valor utilizando pedaços de papel, os participantes comentam a filmagem da cena e riem da situação de medição improvisada do gráfico. É nesse momento que outro participante da sala, Saulo, sentado em uma mesa ao lado, passa a se orientar para a atividade realizada por Tatiana e Éverton, dirigindo-lhes o olhar.

Logo em seguida, Tatiana e Éverton divergem acerca do valor indicado no gráfico. Na linha 161, Tatiana diz que o valor é menor do que 400. Éverton, por sua vez, na linha 162, reitera que é 400, e, diante do questionamento de Tatiana (linha 163), argumenta que o fato de ela estar olhando de lado o gráfico deve estar prejudicando sua percepção (linhas 165). Tatiana, então, deixa Éverton, que está de frente para o computador, medir sozinho. Nesse momento Saulo volta a dirigir o olhar para os participantes. Os três, então, olham-se e sorriem. Finalmente, depois de dois turnos produzidos parcialmente inaudíveis ao transcritor (linhas 169-170), Éverton, na linha 173, afirma que o valor da Ea é de $410 \mathrm{~kJ} / \mathrm{mol}$ : "é. quatrocentos é dez", e não de 400, conforme haviam estimado inicialmente.

Em seguida, no entanto, Tatiana demonstra não estar plenamente satisfeita com o resultado da leitura e com o procedimento de medição utilizado (Excerto 4). Direcionando o olhar para Saulo, a participante apresenta outro possível procedimento de leitura do gráfico para identificar o valor procurado: imprimi-lo e medi-lo com uma régua: ${ }^{13}$ "não dá pra imprimir assim para olhar para esse gráfico ali pegando a régua, fazendo com o lápis e assim" (linhas 186-189). Diante disso, Éverton (linhas 195, 199, 201) sugere medir o gráfico a

${ }^{13}$ Os pesquisadores não dispõem de impressora em sua sala. 
partir do Paint, software de edição e criação de imagens, possibilidade que é prontamente ratificada por Tatiana: "si::m. ah boa idéia" (linha 198).

\section{Excerto 4}

\section{((12 linhas de transcrição omitidas))}

\begin{tabular}{|c|c|c|}
\hline 86 & Tatiana: & $\begin{array}{l}\text { não dá(.h) pra imprimir assim(.h) para olhar } \\
\text { para }\end{array}$ \\
\hline 187 & & esse gráfico ali pegando a régua, fazendo com \\
\hline 188 & & - lápis e assim .hehe ((Tatiana gesticula com os \\
\hline 189 & & braços, olha para Saulo e os dois sorriem)) \\
\hline 190 & & $(0,8)$ \\
\hline 91 & Tatiana: & ó teu calendário Saulo \\
\hline 192 & & (.) ((Tatiana devolve o papel usado para medir o \\
\hline 19 & & gráfico)) \\
\hline 4 & Tatiana: & foi muito útil [ (esse calendário) \\
\hline 195 & Éverton: & [na verdade deveria dar \\
\hline 19 & & um: : um print screen \\
\hline 197 & & $()$. \\
\hline 198 & Tatiana: & $\underline{\text { si::m}} \cdot \underline{\text { ah }}$ boa idéia= \\
\hline 199 & Éverton: & =daí por no: := \\
\hline 0 & Tatiana: & $=$ no paint $=$ \\
\hline 1 & Éverton: & =no paint (lTatiana assente com a cabeça e \\
\hline & & dá início ao procedimento sugerido \\
\hline & & por Éverton)) \\
\hline
\end{tabular}

Tatiana imediatamente começa a transferir a imagem do gráfico para o Paint. Por meio desse software a participante inicia o traçado de retas sobre o gráfico, conforme haviam tentado fazer de modo improvisado anteriormente, com pedaços de papel (Figura 5). 
FIGURA 5 - Tatiana executando em um software de edição de imagem o procedimento sugerido por Éverton

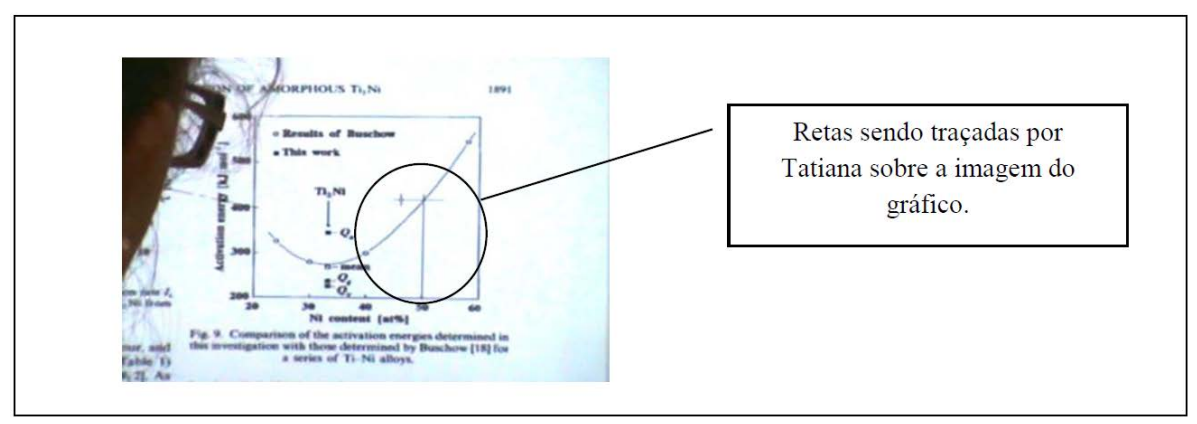

Fonte: imagem captada pela autora a partir dos registros audiovisuais.

A partir desse traçado, Tatiana sugere que o valor procurado é maior do que 400. Diante disso, Éverton volta a se sentar ao lado dela, em frente ao computador. Os dois tornam a analisar o gráfico conjuntamente, trazendo novamente para a interação a necessidade de confirmar a informação procurada, conforme acompanhamos no Excerto 5.

\section{Excerto 5}

((18 linhas de transcrição omitidas))

$\begin{array}{lll}222 & \text { Tatiana: } & \text { vai dar acho que bem mais } \\ 223 & & (0,4) \\ 224 & \text { Éverton: } & \text { vai? ((Éverton senta-se ao lado de Tatiana)) } \\ 225 & & (0,5) \\ 226 & \text { Tatiana: } & \text { vai dar bem mais acho que quatrocentos } \\ 227 & \text { Éverton: } & \text { não é esse aqui? } \\ 228 & \text { Tatiana: } & \text { é: t tá mas: : tá vai, coloca ali, } \\ 229 & & (.) \text { ( Éverton pega o mouse do computador)) } \\ 230 & \text { Tatiana } & \text { daí do ponto vê se tu consegue traçar uma } \\ 231 & & \text { reta (Éverton conclui o traçado das retas } \\ 232 & & \text { sobre o eixo 'y')) }\end{array}$

$\mathrm{Na}$ sequência da interação, com as retas traçadas sobre os eixos do gráfico, Éverton estima novamente, por meio de uma análise visual, um valor de Ea entre 415 e $420 \mathrm{~kJ} / \mathrm{mol}$, valor de fato maior do que o estimado desde o início da interação. Tatiana prefere não palpitar, por não se considerar muito 
boa em estimativa. Nesse momento, Saulo volta a se orientar para Éverton e Tatiana, direcionando o olhar a eles. Éverton, diante disso, solicita-lhe um palpite, conforme acompanhamos no Excerto 6.

\section{Excerto 6}

\section{((19 linhas de transcrição omitidas))}

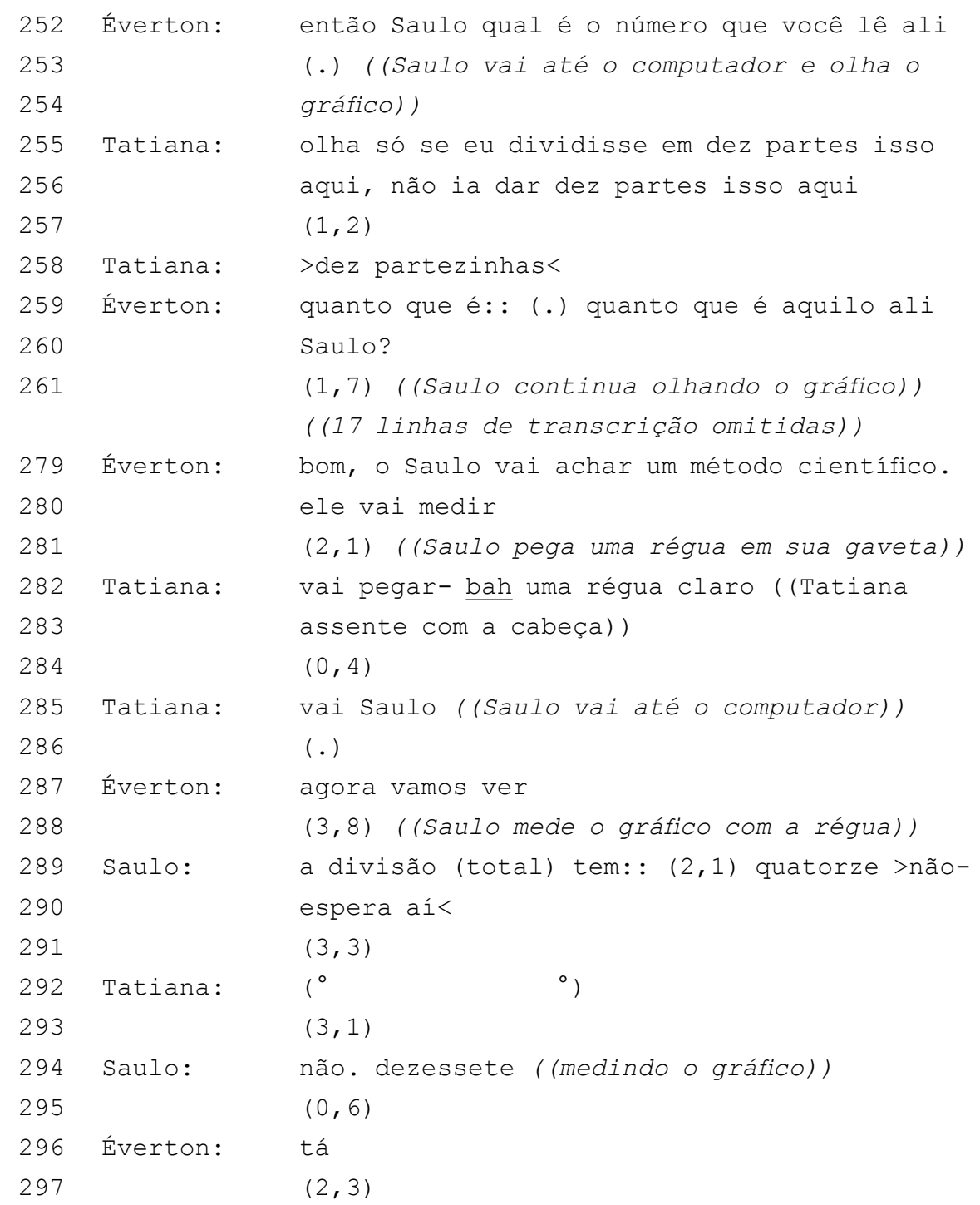




\begin{tabular}{|c|c|c|}
\hline 298 & Éverton: & e:: : o trecho [ ( \\
\hline 299 & Saulo: & [faz três dividido por \\
\hline 300 & & Dezessete \\
\hline 01 & & $(1,4)$ \\
\hline 02 & Éverton: & três por dezessete é vinte, porque \\
\hline 03 & & três vírgula quatro por dezessete daria vinte= \\
\hline 4 & Tatiana: & $=$ vinte \\
\hline 5 & & $(0,6)$ \\
\hline 6 & Éverton: & então é quatrocentos e vin[te.= \\
\hline 307 & Tatiana: & [sim. o ouro hein \\
\hline & Éverton: & hãhãhã ((Saulo e Tatiana sorriem; Tatiana e \\
\hline & & Éverton retomam a montagem da equação)) \\
\hline
\end{tabular}

Saulo passa, então, a engajar-se também na leitura que seus colegas vinham tentando levar a cabo. O participante levanta-se de sua mesa, vai até o computador em frente o qual Tatiana e Éverton estão e passa a observar o gráfico. Diante da afirmação de Tatiana a respeito da impossibilidade de dividir o gráfico em 10 partes iguais para medi-lo e da nova solicitação de Éverton ("quanto que é: : (.) quanto que é aquilo ali Saulo?", linhas 259-260), Saulo, ao longo das 17 linhas de transcrição omitidas, volta a sua mesa em busca de uma régua. Num movimento de complementação do procedimento de leitura que já vinha experimentando por meio da manipulação do gráfico no Paint, o participante apresenta a possibilidade de medir o gráfico já editado por Tatiana e Éverton usando uma régua, no que é ratificado pelos demais participantes (linhas 279-287). Saulo se abstém de simplesmente palpitar um valor por meio de uma análise visual da imagem, e propõe um procedimento que garanta uma leitura mais precisa do gráfico, conforme o próprio participante Éverton destaca nas linhas 279-280: "bom, ○ Saulo vai achar um método científico. ele vai medir".

A partir da medição realizada, Saulo solicita a Tatiana e Éverton que dividam 3 por 17 (linhas 299-300). Depois de uma breve pausa, Éverton aponta que o resultado é 20 e que, então, o valor da Ea seria, de fato, maior do que 400: "então é quatrocentos e vinte." (linha 306). Tatiana, na linha 298, ainda em rápida sobreposição ao turno anterior de Éverton, concorda com o cálculo e comenta, em tom de voz parcialmente inaudível 
ao transcritor: "sim. ô ouro hein" (linha 307). Éverton, então, ri, enquanto Tatiana e Saulo sorriem (linhas 308-309).

Engajados na atividade de leitura que vinham realizando, os participantes encontram ao final desse segmento interacional, por meio do procedimento de leitura do gráfico construído conjuntamente, um valor com o qual demonstram finalmente estar satisfeitos. É com base no valor de $420 \mathrm{~kJ} / \mathrm{mol}$, identificado ao final de toda a sequência, que os participantes Tatiana, Éverton e Saulo encerram a atividade de leitura do gráfico e retomam a resolução da equação que, pela falta da informação da Ea, havia ficado suspensa.

No segmento que analisamos nesta seção, argumentamos que os participantes se envolvem em um evento de letramento, visto que se engajam em uma atividade de leitura referenciada pelo material escrito. Além disso, a atividade realizada pelos participantes constitui um evento de letramento multimodal, uma vez que: (a) se envolvem na leitura de um material gráfico em que a imagem - não a palavra escrita - é o foco de atenção, embora a escrita esteja subjacente, ainda que de modo periférico; (b) realizam a leitura da imagem em um "espaço de escrita" (SOARES, 2002) diferente do papel impresso, que lhes apresenta um material visual em um espaço virtual (um gráfico na tela do computador); (c) interagem a partir desse material visual e virtual de um modo novo, negociado de maneira contingente e emergente, quando lançam mão de diferentes ações para dar conta da leitura em que estão engajados.

Ao longo desse evento de letramento, os participantes orientam-se a uma demanda de resolução de um problema prático que se coloca no aqui-eagora da interação: encontrar o valor da Ea do nitinol que permita continuar a resolução de uma equação que vinham calculando. $\mathrm{Na}$ busca por essa informação, os participantes encontram, ao final de uma pesquisa realizada conjunta e colaborativamente, um gráfico a partir do qual julgam ser possível identificar o valor procurado. A partir dele, engajam-se em uma atividade de leitura em meio à qual emerge a necessidade de construção conjunta de um procedimento que lhes possibilite obter com alguma precisão a informação procurada.

Nesse empreendimento, os participantes se orientam para a necessidade de confirmar o valor de $400 \mathrm{~kJ} / \mathrm{mol}$, estimado inicialmente com base apenas em uma análise visual do gráfico. Diante disso, lançam mão de 
diferentes ações que conduzem à construção conjunta de um procedimento e, assim, ao avanço da leitura:

(1) Inicialmente, Éverton e Tatiana procuram identificar o valor da Ea improvisando com dois pedaços de papel o traçado de retas sobre os eixos do gráfico, o que leva Éverton a identificar um valor de $410 \mathrm{~kJ} /$ mol de Ea.

(2) Tatiana, no entanto, ao final dessa primeira tentativa, demonstra não estar plenamente satisfeita com o resultado da leitura e com o procedimento utilizado, quando sugere imprimir o gráfico e lê-lo por um método convencional de medição com régua e lápis.

(3) Éverton, então, orienta-se para a insatisfação manifestada por sua interlocutora quando sugere manipular o gráfico em um software de edição de imagem (Paint) que possibilite, assim, traçar retas não mais improvisadas com pedaços de papel sobre os eixos.

(4) A sugestão é prontamente ratificada por Tatiana, que, ao realizar o procedimento sugerido por seu interlocutor, recoloca a necessidade de confirmar o valor da Ea, por estimar que o valor indicado pelo gráfico seja maior do que $410 \mathrm{~kJ} / \mathrm{mol}$, valor encontrado anteriormente.

(5) Éverton e Tatiana voltam, assim, a analisar o gráfico editado com as retas sobre os eixos e, diante da dificuldade em precisar o valor, pedem ajuda ao participante Saulo.

(6) Saulo, atendendo ao pedido de ajuda, propõe medir o gráfico editado por Tatiana e Éverton com uma régua, proposta que é ratificada pelos demais.

(7) A partir das medidas obtidas por Saulo, os participantes realizam um cálculo conjunto, obtendo o valor de $420 \mathrm{~kJ} / \mathrm{mol}$ - resultado com o qual os participantes demonstram, finalmente, ficar satisfeitos, uma vez que é com base nele que encerram a atividade de leitura e retomam a atividade suspensa de resolução da equação.

Engajados na leitura do gráfico, os dois participantes produzem conhecimento conjuntamente na medida em que constroem conjuntamente, ao longo da interação, um procedimento de leitura satisfatório para seus propósitos situados que lhes possibilita obter com alguma precisão a informação que lhes falta para dar continuidade à atividade suspensa de resolução de uma equação. A construção desse conhecimento é resultado 
de um esforço conjunto dos participantes que, visivelmente engajados em um empreendimento comum, produzem localmente esse procedimento, procurando dar conta da necessidade, tornada relevante por eles próprios em suas ações, de confirmar o valor preciso da Ea procurado desde o início do segmento. Trata-se, nos termos de Abeledo (2008), de uma "realização pública, emergente e contingente" (p. 160), produzida pelos participantes para levarem a cabo as atividades em que estão engajados no aqui-e-agora daquela interação, sendo observável nas ações por meio das quais os participantes exibem sua orientação para o trabalho de construção conjunta de um conhecimento pela construção conjunta de um procedimento de leitura.

\section{Considerações finais}

Neste trabalho buscamos aliar, por meio da análise de um dado de falaem-interação, os entendimentos de letramento e de construção conjunta de conhecimento enquanto realizações sociais instanciadas na interação. Nesses termos, buscamos caracterizar de modo situado um evento de letramento multimodal e demonstrar como nesse evento é possível flagrar a construção conjunta de conhecimento entre os participantes.

A análise demonstra que, no segmento interacional analisado, os participantes se envolvem em evento de letramento multimodal na medida em que se engajam em uma atividade de leitura de um material visual considerando um espaço de escrita virtual. Envolvidos nessa atividade, os participantes constroem conhecimento conjuntamente na medida em que constroem em conjunto um procedimento de leitura de um gráfico que lhes possibilita acessar a informação buscada desde o início do segmento.

Este trabalho busca contribuir com estudos sobre o letramento que adotam o entendimento de letramento como ato social e com pesquisas que têm dado atenção à multimodalidade em suas investigações sobre práticas letradas na contemporaneidade. Ademais, acreditamos que, por meio de nossa análise, o leitor possa refletir a respeito de como eventos de letramento multimodais podem conduzir a um "estado" ou "condição" particulares em relação a práticas de leitura e de escrita impressos, "na cultura do papel" (SOARES, 2002, p. 146).

Além disso, o presente trabalho vai ao encontro de pesquisas que têm buscado demonstrar um entendimento praxeológico de construção 
conjunta de conhecimento, que é passível de descrição pela análise das ações por meio das quais os participantes se orientam para essa atividade (GARCEZ, FRANK, KANITZ, 2012a) e que pode ser flagrada, conforme aqui argumentamos, também em eventos de letramento (multimodais).

\section{Contribuição das autoras}

Andréia Kanitz: redigiu o resumo/abstract; elaborou a introdução, a seção de revisão teórica sobre a perspectiva sociointeracional de construção conjunta de conhecimento e a seção de procedimentos metodológicos (segmentação, transcrição e análise do dado pela perspectiva dos participantes); elaborou a seção de análise do dado interacional pela perspectiva teórico-metodológica da Análise da Conversa Etnometológica enquanto instância de construção conjunta de conhecimento desde uma perspectiva sociointeracional; redigiu a seção de considerações finais; procedeu a todas as revisões solicitadas pelos pareceristas e à edição da versão final do texto.

Raquel Leão Luz: redigiu seção de revisão teórica sobre letramento e letramento multimodal; elaborou a seção de análise do dado interacional pela perspectiva dos estudos sobre letramento; elaborou as considerações finais.

\section{Referências}

ABELEDO, M. O. L. Uma compreensão etnometodológica da aprendizagem de lingua estrangeira na fala-em-interação de sala de aula. 2008. Tese (Doutorado em Letras) Universidade Federal do Rio Grande do Sul, Porto Alegre, 2008.

ANTAKI, C. Producing a 'cognition'. Discourse Studies, Thousand Oaks, v. 8, n. 1, p. 9-15, 2006. Doi: https://doi.org/10.1177/1461445606059545

ATKINSON, J. M.; HERITAGE, J. Structures of Social Action. Cambridge: Cambridge University Press, 1984.

BARTON, D. Directions for Literacy Research: Analysing Language and Social Practices in a Textually Mediated World. Language and Education, New York, v. 15, n. 2-3, p. 92-104, 2001. Doi: https://doi.org/10.1080/09500780108666803

BARTON, D. Literacy: An Introduction to the Ecology of Written Language. 2. ed. Oxford: Blackwell, 2007.

COOK-GUMPERZ, J. The Social Constructions of Literacy. New York: Cambridge University Press, 2006. Doi: https://doi.org/10.1017/CBO9780511617454 
FRANK, I. Constituição e superação de momentos desconfortáveis em sequências de convites à participação: a construção do engajamento na fala-em-interação de sala de aula. 2010. Dissertação (Mestrado em Letras) - Universidade Federal do Rio Grande do Sul, Porto Alegre, 2010.

FRANK, I. Fala-em-interação e comunidades de aprendizagem. Projeto de pesquisa submetido ao CNPq para renovação de Bolsa de Produtividade em Pesquisa. Porto Alegre: UFRGS, 2010. Manuscrito inédito.

GARCEZ, P. M. Transcrição como teoria: a identificação dos falantes como atividade analítica plena. In: LOPES, L. P. M.; BASTOS, L. C. (Org.). Identidades: recortes multi e interdisciplinares. Campinas: Mercado de Letras, 2002. p. 83-95.

GARCEZ, P. M.; FRANK, I.; KANITZ, A. Interação social e etnografia: sistematização do conceito de construção conjunta de conhecimento na fala-eminteração de sala de aula. Calidoscópio, São Leopoldo, v. 10, n. 2, p. 211-224, 2012 a. Doi: https://doi.org/10.4013/cld.2012.102.08

GARCEZ, P. M.; FRANK, I.; KANITZ, A. Produção conjunta de conhecimento em um cenário de desenvolvimento de tecnologia. Veredas, Juiz de Fora, v. 16, n. 1, p. 166-184, 2012b.

GARCEZ, P. M.; SALIMEN, P. G. Pedir e oferecer ajuda para “fazer aprender" em atividades pedagógicas de encenação na fala-em-interação de sala de aula de inglês como língua adicional. In: BARCELOS, A. M. (Org.). Linguística aplicada: reflexões sobre ensino e aprendizagem de língua materna e língua estrangeira. Campinas: Pontes, 2011. p. 97-117.

HEATH, S. B.; STREET, B. V. On Ethnography: Approaches to Language and Literacy Research. New York: Teachers College Press, 2008.

LODER, L. O modelo Jefferson de transcrição: convenções e debates. In: LODER, L.; JUNG, N. (Org.). Fala-em-interação social: introdução à análise da conversa etnometodológica. Porto Alegre: Mercado de Letras, 2008. p. 127-162.

LODER, L. L.; JUNG, N. M. (Org.). Fala-em-interação social: introdução à análise da conversa etnometodológica. Porto Alegre: Mercado de Letras, 2008.

MAYNARD, D. Cognition on the ground. Discourse Studies, Thousand Oaks, v. 8, n. 1, p. 105-115, 2006. Doi: https://doi.org/10.1177/1461445606059560

MONDADA, L. La competence comme dimension situee et contingente, localement évaluée par les participants. Bulletin Suisse de Linguistique Appliquée, Neuchâtel, n. 84, p. 1-37, 2006. 
MONDADA, L.; DOEHLER, S. P. Second Language Acquisition as Situated Practice: Task Accomplishment in the French Second Language Classroom. Modern Language Journal, Hoboken, v. 88, n. 4, p. 501-518, 2004. Doi: https://doi. org/10.1111/j.0026-7902.2004.t01-15-.x

OCHS, E.; SCHEGLOFF, E. A.; THOMPSON, S. A. (Org.). Interaction and Grammar. Cambridge: Cambridge University Press, 1996. Doi: https://doi. org/10.1017/CBO9780511620874

SALIMEN, P. G. A atividade pedagógica de encenar em grupos na sala de aula de língua estrangeira: pedidos de ajuda, ofertas de ajuda e aprendizagem. 2009. Dissertação (Mestrado em Letras) - Universidade Federal do Rio Grande do Sul, Porto Alegre, 2009.

SCHEGLOFF, E. A. Conversation Analysis and Socially Shared Cognition. In: RESNICK, L; LEVINE, J.; BEHREND, S. (Org.). Perspectives on Socially Shared Cognition. Washington: American Psychological Association, 1991. p. 150-171. Doi: https://doi.org/10.1037/10096-007

SCRIBNER, S.; COLE, M. The Psycology of Literacy. Cambridge: Harvard University Press, 1981. Doi: https://doi.org/10.4159/harvard.9780674433014

SOARES, M. Novas práticas de leitura e escrita: letramento na cibercultura. Revista Educação e Sociedade, Campinas, v. 23, n. 81, p. 143-160, dez. 2002. Doi: https://doi. org/10.1590/S0101-73302002008100008

SOARES, M. Letramento: um tema em três gêneros. Belo Horizonte: Autêntica, 2006.

STREET, B. Literacy in Theory and Practice. Cambridge: Cambridge University Press, 1984.

STREET, B. What's New in New Literacy Studies? Critical Approaches to Literacy in Theory and Practice. Current Issues in Comparative Education, London, v. 5, n. 2, p. 77-91, 2003.

STREET, B. V.; CASTANHEIRA, M. L. Práticas e eventos de letramento. In: FRADE, I. C. A. S.; VAL, M. G. C.; BREGUNCI, M. G. C. (Org.). Glossário Ceale: termos de alfabetização, leitura e escrita para educadores. Belo Horizonte: UFMG/ Faculdade de Educação, 2014. Disponível em: <http://www.ceale.fae.ufmg.br/ app/webroot/glossarioceale/verbetes/praticas-e-eventos-de-letramento>. Acesso em: 5 mar. 2019. 


\section{Anexo A - Convenções de transcrição*}

\begin{tabular}{|c|c|c|}
\hline . & (ponto final) & entonação descendente \\
\hline$?$ & (ponto de interrogação) & entonação ascendente \\
\hline , & (vírgula) & entonação de continuidade \\
\hline- & (hífen) & marca de corte abrupto \\
\hline$\uparrow \downarrow$ & (flechas para cima e para baixo) & $\begin{array}{l}\text { alteração do tom de vOz (mais agudo: } \\
\text { para cima; mais grave: para baixo) }\end{array}$ \\
\hline : & (dois pontos) & prolongamento do som \\
\hline nunca & (sublinhado) & som enfatizado \\
\hline PALAVRA & (maiúsculas) & fala em volume alto \\
\hline${ }^{\circ}$ palavra ${ }^{\circ}$ & (sinais de graus) & fala em voz baixa \\
\hline$>$ palavra $<$ & (sinais de maior e menor) & fala acelerada \\
\hline$<$ palavra $>$ & (sinais de menor e maior) & fala desacelerada \\
\hline hh & (série de h's) & aspiração ou riso \\
\hline .hh & (h's precedidos de ponto) & inspiração audível \\
\hline [ ] & (colchetes) & fala simultânea ou sobreposta \\
\hline$=$ & (sinais de igual) & elocuções contíguas \\
\hline$(2,4)$ & (números entre parênteses) & $\begin{array}{l}\text { medida de silêncio (em segundos e } \\
\text { décimos de segundos) }\end{array}$ \\
\hline (.) & (ponto entre parênteses) & micropausa, até $2 / 10$ de segundo \\
\hline$(\quad)$ & (parênteses vazios) & $\begin{array}{l}\text { segmento de fala que não pôde ser } \\
\text { transcrito }\end{array}$ \\
\hline (palavra) & $\begin{array}{l}\text { (segmento de fala entre } \\
\text { parênteses) }\end{array}$ & transcrição duvidosa \\
\hline ((olhando para o teto $))$ & (parênteses duplos) & descrição de atividade não-vocal \\
\hline
\end{tabular}

*Adaptado de Atkinson e Heritage (1984, p. ix-xvi), Ochs, Schegloff e Thompson (1996, p. 461-465) e das instruções para submissão de artigos ao periódico especializado Research on Language and Social Interaction.

Data de submissão: 14/06/2018. Data de aprovação: 11/02/2019. 